\title{
The World after COVID
}

\author{
Manfred Max Bergman (1)
}

Chair of Social Research and Methodology, Head of the Social Transitions Research Group, University of Basel, 4501 Basel, Switzerland; max.bergman@unibas.ch

Received: 24 June 2020; Accepted: 24 June 2020; Published: 25 June 2020

\section{Oh, wonder!}

How many goodly creatures are there here!

How beauteous mankind is!

O brave new world, that has such people in't!

William Shakespeare, The Tempest

For months, the global health crisis and its emergent consequences have swallowed our lives. Directly and indirectly, Covid is defining our daily routines and challenges, and it is shaping our fears and hopes for the future. Concurrently, and seemingly independent of the pandemic, the killing of George Floyd in Minneapolis sparked outrage well beyond the US. Hundreds of thousands of people joined protests against police brutality and structural racism on most continents. A closer inspection between these crises reveals interlinkages and leads us to recognize common denominators. We must also admit that the current health and political crises are not only the consequence of pre-existing global trends, but also contributors to the evolving economic, political, social, and humanitarian crises. The roots of our individual, collective, and regional challenges lie much deeper, and many of the underlying challenges will remain well beyond the current pandemic. Whatever "after Covid" may mean (e.g., discovering an effective vaccine, trading it for profit or favour, administering it to every human on earth, or adjusting our lives because an effective vaccine may prove elusive), we find ourselves at a fork in the road: We cannot remain where we are, there is no way back, and all paths that lie ahead will have significantly different consequences not only for our individual lives and societies, but especially for the wellbeing of future generations. Despite differing options and consequences, no nation will be spared.

The trends defining the shape and experience of our current and emerging crises are pervasive, omnipresent, and interdependent: We have privatized and monetized public goods and services. We have socialized risks and privatized profits. We continue to degrade and destroy the environment while depleting finite resources. Our economic and political arrangements drive climate change, mass migration, and water and food insecurity. We are witnessing a rise in populism, regionalism, nationalism, and tribalism, and many now favour unilateralism and bilateralism at the expense of multilateralism. We seem unable or unwilling to fight increasing corruption, abuse of power, elite failures, and erosion of public trust. In short, we are at a systemic tipping point, transitioning economically, politically, socially, and culturally into a new normal. But could the pandemic be that "rare but narrow window of opportunity to reflect, reimagine, and reset our world", as Klaus Schwab, the founder and chairman of the World Economic Forum, recently proposed?

In Chinese, the word crisis decomposes into two characters, 危机, which signify danger at a juncture or a point where things change. What would a new world look like, after Covid (AC)? What kind of capitals, materials, technologies, and skills will we have and need to reimagine and reset the world? Currently, four imaginaries seem to compete against each other: 


\section{Econo-Centric Societies}

In this imaginary, societies seek to return to BC (Before Covid) in that they hitch their destiny to a narrow selection and reinterpretation of tenets derived from the liberal market economy paradigm. Aiming to prevent failures of certain markets or businesses deemed system-relevant, this imaginary inevitably appoints the state as the referee, and politicises economic interests as guiding principles. Governments and central banks will cooperate to stimulate, bail out, or tax specific industries and sectors. As governments are co-opted to back narrow and selected private sector interests to bolster short-term economic stability and employment rates, this imaginary exacerbates the distortion of markets and the already flawed assumption of trickle-down wealth generation. National deficits will continue to balloon, inevitably leading to an increase in the concentration of wealth and a worsening of conditions for the poor and the middle classes. In socializing risks and costs while privatizing profits, this econo-centric imaginary, AC, is likely to be associated with tariffs, corporate tax reductions, and the deregulation of labour markets and environmental protection. In the race to the bottom, social development and environmental protection will be sacrificed for short-term economic stability and for long-term private wealth creation and protection of privilege for the very few.

\section{Enviro-Centric Societies}

In this scenario, the pandemic will initiate an ambitious sustainable development agenda based on environmental and climate mitigation concerns. The Green New Deal as sponsored by US Representative Alexandria Ocasio-Cortez, or its British variant supported by the former Labour leader Jeremy Corbyn are prominent examples. It is modelled loosely after Franklin D. Roosevelt's New Deal, which aimed to counter the detrimental effects of the Great Depression of the 1930s. A strict enviro-centric imaginary would structurally reallocate human and financial resources to develop green technologies and infrastructure to primarily mitigate climate change, protect finite resources, and, to a lesser extent, economic inequality. While there are clearly many advantages associated with a narrow sustainability perspective, two significant drawbacks stand out: On the one hand, the enviro-centric imaginary places the state at the helm of business, society, and the environment. On the other, and perhaps more concerning, this top-down strategy will most likely impose restrictions on current business models, markets, consumer preferences, and voter choices.

\section{Socio-Centric Societies}

Central to a socio-centric imaginary is social development and collective prosperity, which would require a reorientation of national policies to prioritise and, to some extent, nationalize public goods and services in the interest of collective justice, equality, and stakeholder capitalism. Restoring the social contract and providing generous social welfare and safety nets AC would need a strong state and at least a partial nationalisation of essential public goods, services, and infrastructure associated with health, education, energy, mobility, communication, and others. A socio-centric imaginary would require significant wealth redistributions and tax reforms, state intervention across most sectors, and a degree of populism that may not be in the interest of efficiency and environmental protection. In the long run, a strong socio-centric variant may indeed hamper exactly that which it aims to foster: social development and collective prosperity.

\section{Techno-Centric Societies}

The fourth imaginary, often heralded as the bright new future among higher income countries, is closely associated with the 4 th Industrial Revolution. It promises prosperity through socio-technical advancement, notably big data, the internet of things, artificial intelligence, robotics, automation, and genetic technologies. While econo-centric societies tend to preserved established industries and sectors, techno-centric societies bank on disrupting industries and new unicorns, start-up companies valued at USD 1 billion or more. To some extent, the Green Deal proposed by the EU embraces many 
core ideas associated with techno-centric and enviro-centric imaginaries. While our growing access to information and technology continues to improve the quality of most lives, many difficulties lie ahead as most socio-technological advances challenge prevailing social norms, ethical sensitivities, as well as technological and economic boundaries. Unchecked, this imaginary risks creating much greater inequalities, mass unemployment, and unregulated control within and between countries.

These four imaginaries are mere abstractions, ideal types that would not be found in a lived environment. They are mutually exclusive only in theory. Whichever our world and societies embrace $\mathrm{AC}$, the new normal will integrate elements from different imaginaries. Each imaginary has its major shortcomings, incurs different costs, creates different opportunities, and leads to different destinies. Each will be costly and painful, and each will create winners and losers.

Whether we model the new normal along the lines of one of these four imaginaries, develop a fifth, or construct a hybrid, there are seven conditions that will or ought to define our path: First, whether we like it or not, the state will play an increasingly directive role in the private sector, formulating new or reformulating existing relations between business and society. Consequently, we need to find better ways to deal with the increasing interdependence between the public and private sectors. This will require rethinking and expanding contemporary practices on regulation, transparency, stakeholder engagement, and governance. Second, any sustainable future must include a concern for local, national and global provisions for healthcare, education, and prosperity. Despite the current tendency toward unilateral and bilateral problem solving or rent seeking, and despite talk about deglobalization and self-sufficiency, the globalized world will no longer permit the accumulation of considerable wealth of a small number of nations or actors at the expense of all others - at least not peacefully. Third, any imaginary aiming for a more sustainable future must include the interests of businesses, consumers, and voters. Fourth, any solution must make these stakeholders not only accountable but also willing participants in the pursuit of long-term stability and prosperity. Fifth, the sooner we realize that each region and nation is in the middle of a paradigm shift that requires system-wide, long-term, transnational cooperation - beyond a narrow focus on quarterly earning spreadsheets, stock market indices, and election cycles - the more sustainable a solution may be. Sixth, whichever road we take forward, rebuilding AC will be a difficult, costly journey. Seventh, geopolitical and geoeconomic shifts must be accompanied by context-specific and culture-sensitive solutions. Generic debates on sustainability and climate change mitigation must give way to nuanced debates on capabilities and adaptation of sectors, regions, and communities.

\section{Global Inequality AC}

Most global economic and political arrangements do not adequately take into account the interests, opportunities, and challenges of lower and most middle income countries. Yet despite this imbalance, higher income countries are profoundly underprepared to deal with large-scale shocks and scarcity. In contrast, many lower income countries are far more practiced, adaptable, and resilient; able to identify, develop, and implement innovative, low-cost solutions. In our time of the great reset, and considering the mobility of data, information, ideas, technologies, and industries, most lower and middle income countries are well positioned to forge alliances toward national and regional development. Their greatest challenges AC will include the devaluation of currencies and commodities, the restructuring of global supply chains, the decline of the tourism industry and foreign remittances, drops in credit ratings, food and water insecurity, structural unemployment, and, the world's greatest twin challenges in the 21st century: inequality and climate change. The world is changing, as are the rules of engagement in the 21st century. To find a new way forward and to create a new world, we need truth and facts, science and innovation, expertise and excellence, debate and plurality, collaboration and open-mindedness, and civic values and solidarity.

World (ISSN 2673-4060) is a multidisciplinary and open access journal devoted to past, present, and future links between economic, political, social, or environmental issues. World serves as a scholarly forum and source of information on local, regional, national, and international trends, challenges, 
and opportunities relating to sustainability, adaptation, the 4th Industrial Revolution, the Green Deal, and other important developments of our time. We encourage scholars from the natural sciences, engineering and technology, medical and health sciences, agricultural sciences, social sciences, and the humanities to submit papers on sustainable policies, sustainable business, and sustainable societies. We publish original research articles, theoretical papers, position papers, reviews, communications, short notes, and research proposals and ideas.

Our editorial board, section editors, reviewers, and the editorial office of World are looking forward to working with you, and to developing an important resource, network, and platform for a more sustainable world.

(C) 2020 by the author. Licensee MDPI, Basel, Switzerland. This article is an open access article distributed under the terms and conditions of the Creative Commons Attribution (CC BY) license (http://creativecommons.org/licenses/by/4.0/). 